\title{
A CULTURA DA MANGA SOB DIFERENTES REGIMES DE PROFUNDIDADES DO LENÇOL FREÁTICO EM CONDIÇÕES SUBÚMIDAS ${ }^{1}$
}

\author{
EUGÊNIO FERREIRA COELHO ${ }^{2}$; FRANCISCO DAS CHAGAS OLIVEIRA ${ }^{3}$; CARLOS JOSÉ ARAÚJO DO \\ NASCIMENTO ${ }^{4}$; LÚCIO FLAVO LOPES VASCONCELOS ${ }^{3}$; EUGÊNIO CELSO EMÉRITO ARAÚJO3
}

RESUMO - O conhecimento dos critérios agronômicos de drenagem para a cultura da manga é fundamental na elaboração de sistemas de drenagem para áreas com essa cultura e permite antecipar o seu comportamento sob diferentes níveis de drenagem do solo . O trabalho teve por objetivo avaliar as condições de aeração e umidade do perfil de um solo arenoso (areia franca) sob diferentes regimes de profundidades do lençol freático, para determinação de critérios de drenagem para a cultura da manga, cultivar Keitt. O experimento seguiu um delineamento inteiramente casualizado, com quatro tratamentos (regimes de profundidades do lençol freático às distâncias do dreno de 3,5 m; 10,5 m; 17,5 m e sem presença de lençol freático) e cinco repetições. As profundidades do lençol freático e os teores de água no perfil do solo em cada tratamento foram monitorados durante os períodos chuvosos, em três anos consecutivos (19971999). Não houve diferença significativa entre as produtividades da cultura nos tratamentos. As diferenças nas profundidades do lençol freático, nos tratamentos com drenagem, não foram suficientes para diferenciar o estado da água no solo nesses tratamentos. $\mathrm{O}$ lençol freático, na profundidade média de $1,0 \mathrm{~m}$, durante os cinco ou seis meses de período chuvoso, com recargas temporárias atingindo profundidades próximas da superfície do solo, seguidas de rebaixamento imediato do lençol freático, não foi suficiente para afetar o desenvolvimento e a produtividade da manga.

Termos para indexação: Drenagem, planejamento.

\section{MANGO CROP UNDER DIFFERENT DRAINAGE REGIMES IN SUBHUMID CONDITIONS}

\begin{abstract}
The knowledge of mango crop drainage criteria is fundamental for drainage system planning and for prediction of crop behavior under different drainage levels. The objective of the work was to evaluate air-water status in a sand soil (sand loam) profile under different ground water depths for determination of drainage criteria for mango, Keitt variety. The experiment followed a fully randomized design with four treatments ground water depth regime at distances from drain of 3.5, 10.5 and $17.5 \mathrm{~m}$ and under no ground water) and five replications. Ground water depths and water content in the soil profile were monitored during raining seasons of three consecutive years $(1997$ - 1999). There was no significant difference among crop yields from treatments. The differences among ground water depths from treatments were not enough to result different soil water conditions in these treatments. The Ground water at average depth of $1.0 \mathrm{~m}$, with transient recharges reaching soil surface followed by immediate discharge was not enough to affect development and yield of mango.
\end{abstract}

Index terms: Drainage, system planning.

\section{INTRODUÇÃO}

No Brasil, a manga é cultivada em todas as regiões fisiográficas, com destaque para o Nordeste, que apresenta excelentes condições para o seu desenvolvimento e produção. Em 1996, a produção nordestina de manga participou com 47,7\% da produção brasileira. O Piauí contribui com uma área plantada de 1.230 ha (FNP, 2000) e a microrregião de Teresina abrange a maior parte dessa área, sendo o maior e mais importante pólo de cultivo de manga da Região Meio-Norte do Brasil. Onde quer que a manga seja cultivada, isto é, tanto no semi-árido, como em regiões subúmidas, têm sido comum limitações no desenvolvimento da cultura, devido à deficiência de drenagem em algumas áreas. Tal problema tem ocorrido tanto em áreas planas de baixadas, como em locais de cotas mais elevadas, como encostas de pequeno declive. A deficiência de drenagem nessas áreas pode ter causas diversas, dentre as quais, a presença da camada impermeável a pequena profundidade, associada ou não a excessos de irrigação, que em casos de solos pouco intemperizados, tem levado a salinização ou solidificação desses. O excesso de umidade no solo, nas áreas mais próximas dos rios, principalmente durante o período chuvoso, também tem caracterizado o problema de drenagem de áreas cultivadas. Esses problemas têm demandado instalação de dispendiosos sistemas de drenagem, para controle da altura do lençol freático, projetados com desconhecimento dos critérios agronômicos de drenagem das culturas. As recomendações técnicas neste sentido limitamse a culturas extensivas e poucas informações se dedicam a fruteiras. Pizarro (1978) apresentou alguns critérios de drenagem, enfatizando o caráter orientativo das informações, pelas quais, três dias após uma chuva ou irrigação, a profundidade do lençol freático deve atingir 1,4 ou $1,5 \mathrm{~m}$ para não afetar significativamente a produtividade de fruteiras.

O excesso de água no solo, ou sua saturação, causa redução das atividades vegetativas da mangueira após 2 a 3 dias, quando os níveis de $\mathrm{O}_{2}$ no solo caem de $20 \%$ a abaixo de 
5\%. Larson et al. (1993) observaram uma redução no crescimento da planta em $94 \%$ para 110 dias de encharcamento, enquanto, para um tempo máximo de 10 dias, a redução no crescimento foi de 57\%. O encharcamento do solo com manga Tommy Atkins causa redução da assimilação líquida de $\mathrm{CO}_{2}$ e da condutância estomatal, e aumenta a concentração subestomatal em 2 a 3 dias. Ocorrem redução no crescimento de raízes e desenvolvimento de lenticelas hipertrofiadas no tronco, o que é influenciado pela concentração de oxigênio na água, sendo mais acentuado para mais baixas concentrações de $\mathrm{O}_{2}$. A deficiência de aeração do solo pode ser suportável por meses, uma vez que a manga é considerada moderadamente tolerante ao enharcamento do solo (Schaffer, 1997; Larson et al., 1992).

O trabalho teve por objetivo avaliar as condições de aeração e umidade no perfil de um solo para diferentes profundidades do lençol freático, visando a gerar subsídios para determinação de critérios de drenagem para a cultura da manga.

\section{MATERIAL E MÉTODOS}

O experimento foi instalado na área irrigada da Fazenda Mangal - Frutas Tropicais de Exportações LTDA, no km 35 da rodovia Teresina - Palmerais, numa área de 11,5 ha de manga cultivar Keitt, irrigada por microaspersão, em solo predominantemente Podzólico Vermelho-Amarelo. Na área experimental, foi instalado um sistema de drenagem subsuperficial, numa área contendo 22 drenos cobertos, na profundidade de 1,5 m e espaçados $35 \mathrm{~m}$ entre si, com comprimento médio de $150 \mathrm{~m}$. As características físicas e físico-hídricas do solo da área experimental são apresentadas na Tabela 1.

$\mathrm{O}$ experimento seguiu um delineamento experimental inteiramente casualizado, com quatro tratamentos e cinco repetições. Os tratamentos consistiram de diferentes regimes de profundidades do lençol freático para as plantas, localizadas a diferentes distâncias em relação ao dreno. A profundidade do lençol freático (PLF), para cada planta, não foi constante ao longo do tempo, mas variou conforme o regime de recarga e descarga do lençol. Os tratamentos referentes às quatro profundidades dinâmicas do lençol freático, conseqüentes da posição em relação ao dreno, foram (Figura 1): T1 - PLF a 3,5 m de distância do dreno lateral coberto; T2 - PLF a 10,5 m de distância do dreno lateral coberto; T3 - PLF a 17,5 m de distância do dreno lateral coberto; T4 - ausência do lençol freático, isto é, assumiu-se sem presença do lençol freático, cuja profundidade, se existente, estaria abaixo da zona radicular. Para avaliação das condições de umidade e

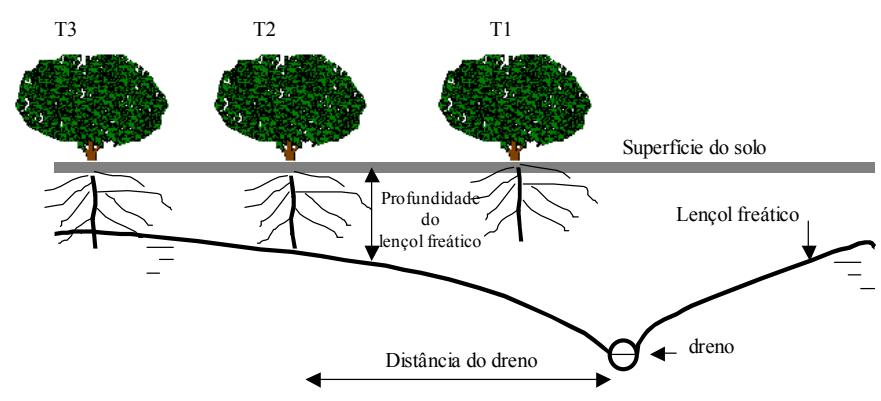

FIGURA 1 - Tratamentos T1, T2 e T3 referentes aos diferentes níveis do lençol freático para as plantas, resultantes da distância destas ao dreno. aeração do solo sob diferentes profundidades do lençol freático, foram instalados dois poços de observação de PVC de $60 \mathrm{~mm}$ de diâmetro (Pizarro, 1978; Millar, 1978). Junto a cada planta, foi também instalado um tubo de acesso para sonda de nêutrons até a profundidade de 1,0 m, para a determinação do teor de água do solo.

O monitoramento dos teores de água do solo e da profundidade do lençol freático foi feito no período chuvoso de 1997, 1998 e 1999, quando ocorreram elevações contínuas do lençol freático. A freqüência de leituras nos poços de observação dependeu do regime pluvial, isto é, houve maior freqüência de leituras em períodos de chuvas constantes e menor freqüência em períodos de chuvas esporádicas. As leituras do teor de água do solo foram feitas na freqüência de sete dias.

Foram monitoradas: (i) a profundidade do lençol freático; (ii) os teores de água do solo nas profundidades de $0,3 \mathrm{~m}, 0,5 \mathrm{~m}$ e 0,7 $\mathrm{m}$; e (iii) com base no teor de água correspondente à saturação do solo, foi avaliada a porosidade drenada nos perfis de solo referentes às profundidades pretendidas do lençol freático, pela equação:

$$
e_{a}=\theta_{s}-\theta
$$

sendo $\mathrm{e}_{\mathrm{a}}$ a porosidade drenada do solo, $\theta_{\mathrm{S}} \mathrm{o}$ teor de água à saturação em base volumétrica $\left(\mathrm{cm}^{3} \cdot \mathrm{cm}^{-3}\right)$ e $\theta$ o teor de água atual do solo $\mathrm{em}^{3} \cdot \mathrm{cm}^{-3}$.

Foram feitas medições biométricas a cada 90 dias nas plantas dos tratamentos T1, T2 e T3, em 1997 e 1998, e também nas plantas do tratamento T4, em 1999. Em novembro de 1999, foi feita a primeira colheita na área, e os frutos foram separados em comerciais (peso do fruto igual ou superior a $285 \mathrm{~g}$ ) e não comerciais (peso inferior a $285 \mathrm{~g}$ ). Foi feita a análise de variância dos dados de produção, que foi associada ao monitoramento do lençol freático e ao teor de água do solo.

\section{RESULTADOS E DISCUSSÃO}

A análise de variância não foi significativa $(\mathrm{P}>0,05)$ para as variáveis de produção relativas aos pesos do total de frutos e de frutos comerciais (Figura 2). A analise foi significativa para números de frutos totais e comerciais, mas o teste de Tukey não mostrou diferença entre as médias dessas variáveis. As produtividades das plantas a $3,5 \mathrm{~m}, 10,5 \mathrm{~m}$ e $17,5 \mathrm{~m}$ do dreno foram satisfatórias, considerando o primeiro ano de colheita no local, tendo sido inclusive um pouco acima em valores absolutos da produtividade sob ausência do lençol freático.

De modo geral, em 1997, a profundidade média do lençol freático entre os drenos (PMLF), em toda a área, esteve, na maior parte do tempo, entre $0,5 \mathrm{~m}$ e $1,0 \mathrm{~m}$, sendo que o encharcamento completo do solo $(\mathrm{PMLF}=0)$ só foi observado em curtos intervalos de tempo (máximo de um dia), com imediata recessão do lençol freático (Figura 3). No período de máxima concentração das precipitações (80-100 dias julianos), a PMLF variou de 0,12 $\mathrm{m}$ a $0,50 \mathrm{~m}$. Nesse ano, além de um regime pluvial mais intenso, ocorreu um razoável número de precipitações acima de $80 \mathrm{~mm}$, chegando a atingir até $100 \mathrm{~mm}$, o que correspondeu a uma recarga do lençol freático equivalente a uma elevação de $0,5 \mathrm{~m}$ (Figura 3). A diferença entre as profundidades médias do lençol freático a 3,5 $\mathrm{m}$ e a $10,5 \mathrm{~m}$ de distância do dreno foi de $0,1 \mathrm{~m}$, e entre as 
profundidades a 10,5 m e 17,5 $\mathrm{m}$ de distância do dreno foi de 0,06 $\mathrm{m}$. No ano de 1998, a PMLF oscilou entre $0,8 \mathrm{~m}$ e $1,5 \mathrm{~m}$ durante todo o período chuvoso estudado. As menores elevações do lençol freático ocorridas em 1998 devem-se ao regime pluvial pouco acentuado, com poucas chuvas, entre $40 \mathrm{e} 70 \mathrm{~mm}$, valores esses capazes de promover elevações entre 0,2 e $0,35 \mathrm{~m}$ no lençol freático (considerando a macroporosidade de $20 \%$ ). A média das diferenças entre as profundidades do lençol freático, a $3,5 \mathrm{~m}$ e a $10,5 \mathrm{~m}$ do dreno, foi de $0,1 \mathrm{~m} \mathrm{e}$, entre as profundidades a $10,5 \mathrm{~m}$ e a $17,5 \mathrm{~m}$, foi de $0,38 \mathrm{~m}$. No período monitorado de 1999 , as profundidades do lençol freático, tanto a $3,5 \mathrm{~m}$ e a $10,5 \mathrm{~m}$ como a $17,5 \mathrm{~m}$, foram superiores a $1,0 \mathrm{~m}$ durante os 55 primeiros dias do ano, reduzindo-se a partir daí, mas mantendo-se numa média de $0,6 \mathrm{~m}$, atingindo a superfície do solo durante apenas um dia. Nesse ano, a diferença entre as profundidades do lençol freático, a 3,5 $\mathrm{m}$ e a $10,5 \mathrm{~m}$ do dreno, foi em média de $0,15 \mathrm{~m}$ e, entre as profundidades a 10,5 e 17,5 m, foi em média de $0,06 \mathrm{~m}$.

As diferenças entre as profundidades do lençol freático, a $3,5 \mathrm{~m}$, a $10,5 \mathrm{~m}$ e a $17,5 \mathrm{~m}$ do dreno, não foram suficientes para gerar diferenças significativas no estado da água do solo nessas condições, sendo que, em 1997, a média das diferenças entre os teores de água no perfil de 0 a $0,6 \mathrm{~m}$, para as distâncias de $3,5 \mathrm{~m}$ e $10,5 \mathrm{~m}$ do dreno, foi de $0,02 \mathrm{~cm}^{3} \cdot \mathrm{cm}^{-3} \mathrm{e}$, para as distâncias de $10,5 \mathrm{~m}$ e $17,5 \mathrm{~m}$, foi de $0,03 \mathrm{~cm}^{3} . \mathrm{cm}^{-3}$. Em 1998, a média das diferenças entre os teores de água no perfil de 0 a $0,6 \mathrm{~m}$, para as distâncias de 3,5 m e 10,5 m do dreno, foi de $0,02 \mathrm{~cm}^{3} \cdot \mathrm{cm}^{-3} \mathrm{e}$, de $10,5 \mathrm{~m}$ e $17,5 \mathrm{~m}$, foi de $0,01 \mathrm{~cm}^{3} . \mathrm{cm}^{-3}$. Em 1999, a média das diferenças entre os teores de água no perfil de 0 a $0,6 \mathrm{~m}$, para as distâncias de 3,5 m e 10,5 m e para as distâncias de 10,5 m e 17,5 $\mathrm{m}$ do dreno, foi de $0,01 \mathrm{~cm}^{3} \cdot \mathrm{cm}^{-3}$.

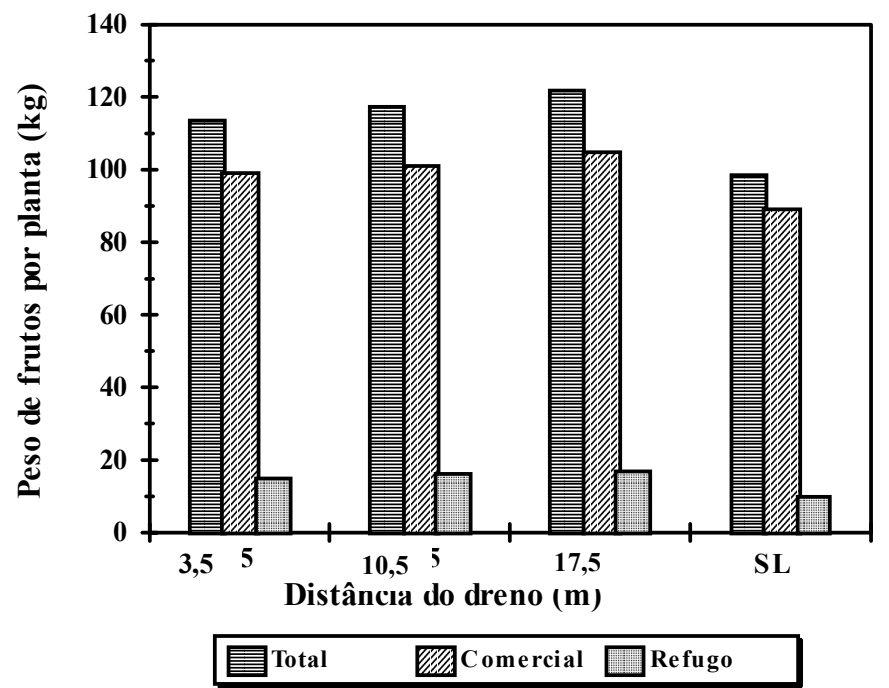

FIGURA 2 - Peso e número de frutos por planta da mangueira Keitt em diferentes distâncias do dreno e na ausência do lençol freático, ao longo do período de maior concentração das precipitações.
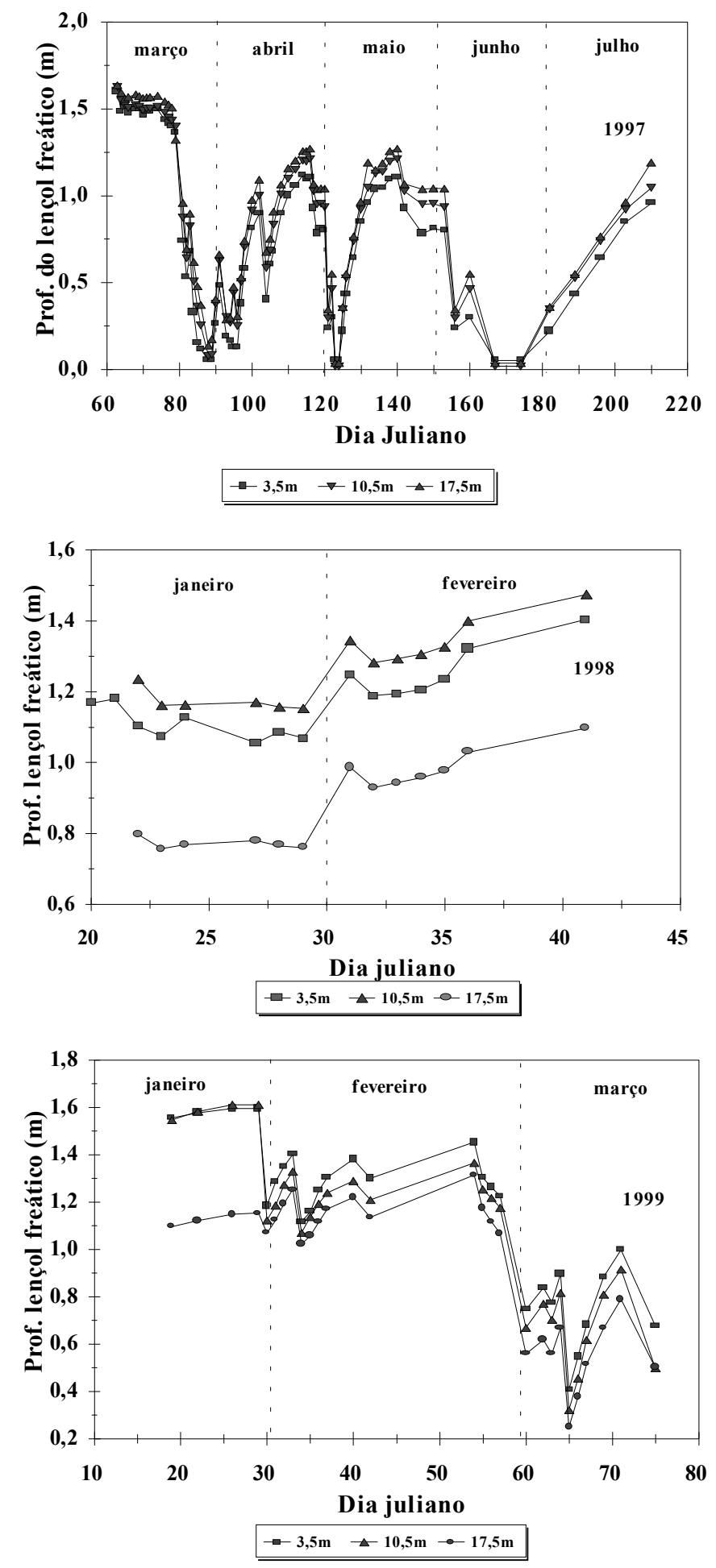

FIGURA 3 - Profundidades médias do lençol freático a diferentes distâncias do dreno, durante os períodos chuvosos de 1997,1998 e 1999.

TABELA 1 - Características físicas e físico-hídricas do solo da área experimental.

\begin{tabular}{|c|c|c|c|c|c|c|c|c|c|}
\hline $\begin{array}{l}\text { Prof } \\
\text { (m) }\end{array}$ & 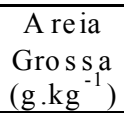 & 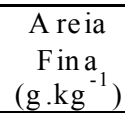 & 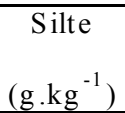 & 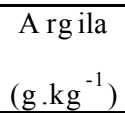 & $\begin{array}{c}\text { Densidade } \\
\text { solo } \\
\left(\mathrm{kg} . \mathrm{dm}^{-3}\right)\end{array}$ & $\begin{array}{c}\text { Teorde } \\
6 \mathrm{kPa} \\
\left(\mathrm{m}^{3} \cdot \mathrm{m}^{-3}\right)\end{array}$ & $\begin{array}{l}\text { água a } \\
1500 \mathrm{kPa} \\
\left(\mathrm{m}^{3} \cdot \mathrm{m}^{-3}\right)\end{array}$ & $\begin{array}{c}\text { Porosidade } \\
\text { Total } \\
\left(\mathrm{m}^{3} . \mathrm{m}^{-3}\right)\end{array}$ & $\begin{array}{c}\text { M a cropor. } \\
\left(\mathrm{m}^{3} \cdot \mathrm{m}^{-3}\right)\end{array}$ \\
\hline $0,0-0,3$ & 280 & 530 & 150 & 40 & 1,54 & 0,1687 & 0,0322 & 0,4031 & 0,2344 \\
\hline $0,3-0,5$ & 300 & 550 & 90 & 60 & 1,58 & 0,1664 & 0,0931 & 0,3875 & 0,2211 \\
\hline $0,5-0,7$ & 340 & 510 & 80 & 70 & 1,58 & 0,2181 & 0,1020 & 0,3875 & 0,1694 \\
\hline
\end{tabular}



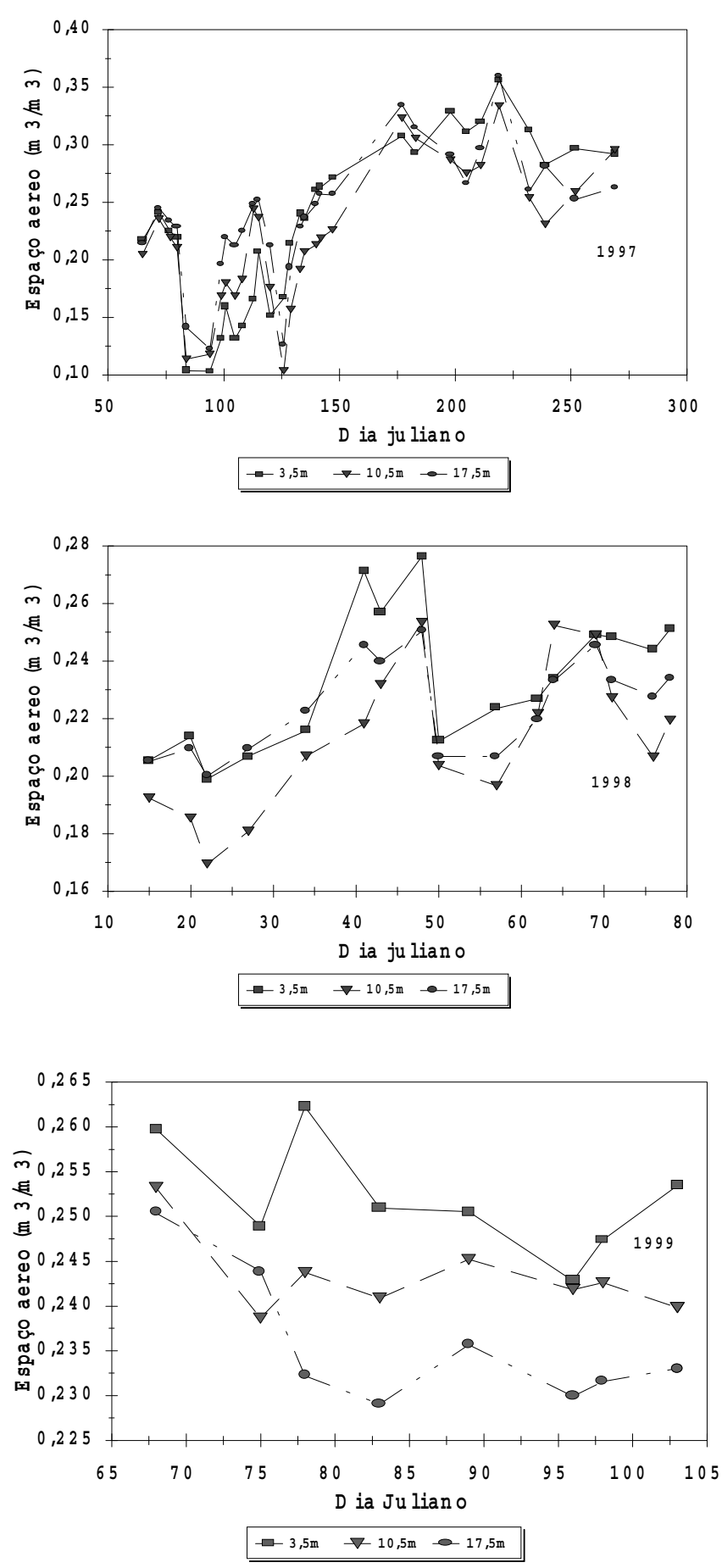

FIGURA 4 - Porosidade drenada média do perfil do solo a diferentes distâncias do dreno, durante os
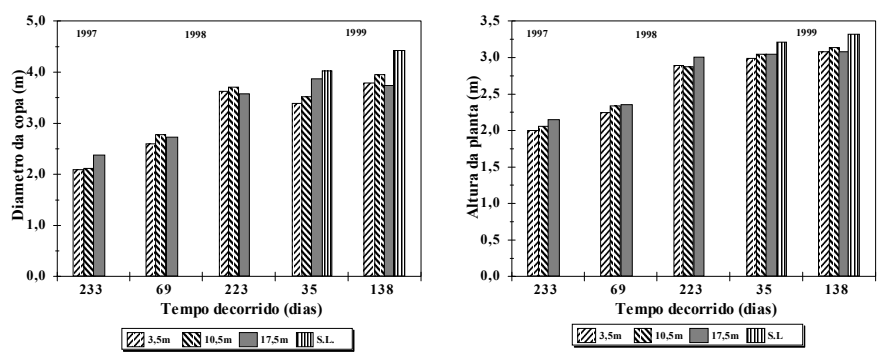

FIGURA 5 - Variáveis biométricas (altura da planta e diâmetro da copa) referentes às plantas localizadas a $3,5 \mathrm{~m}$, $10,5 \mathrm{~m}$ e $17,5 \mathrm{~m}$ do dreno e sem presença de lençol freático, no período de 1997-1999.

No ano de 1997, o período entre 80 e 90 dias foi o que resultou em valores da porosidade drenada do solo mais baixos, atingindo a 10\% (Figura 4). Os espaços aéreos individuais, nesse período, não foram propícios à cultura da manga, tendo atingido $7,5 \%$ na profundidade de $0,5 \mathrm{~m}$ e $5 \%$ na profundidade de $0,7 \mathrm{~m}$. Em 1998, a porosidade drenada, independentemente da posição relativa ao dreno, foi superior a $16 \%$ na maior parte do período avaliado, traduzindo-se em condições normais de arejamento do perfil do solo. Nesse período, as chuvas não foram suficientes para afetar as condições de arejamento do solo, de forma a tornála prejudicial ao desenvolvimento da cultura da manga. Em 1999, no período monitorado, a porosidade drenada foi superior a $22 \%$ em todas as distâncias do dreno estudadas, o que se traduziu em condições de aeração razoáveis para a cultura.

Os baixos valores da porosidade drenada observados nas profundidades entre 0,5 e 0,7 m, em 1997 (Figura 4), não afetaram o crescimento e desenvolvimento da mangueira, o que pode ser observado pela Figura 5, onde os parâmetros biométricos das plantas dos diferentes tratamentos mantiveram-se crescentes em todas as medidas executadas de 1997 a 1999. Deve-se levar em conta que, em 1997, apesar das recargas mais acentuadas do lençol freático, tendo em vista estar a manga no segundo ano após o plantio, as raízes ainda estavam concentradas provavelmente na região superficial do perfil do solo $(0-0,3 \mathrm{~m})$, onde a porosidade drenada se manteve em níveis iguais ou superiores a 9\%. A manga é considerada moderadamente tolerante ao encharcamento (Shaffer, 1997) ou à deficiência de aeração do solo. Períodos curtos de encharcamento não são fatais para a manga, podendo trazer uma pequena redução nas atividades fisiológicas, havendo recuperação imediata após a reaeração do solo.

Os valores de produtividades, tanto de peso como do número dos frutos comerciais e do total de frutos, considerados razoáveis para a cultivar em estudo, associados aos dados de posição do lençol freático, teor de água e porosidade drenada, permitem observar que o desenvolvimento e frutificação da manga, cultivar Keitt, não foi afetado sob condições de lençol freático à profundidade média de $1,0 \mathrm{~m}$, durante os cinco ou seis meses de período chuvoso, com recargas temporárias atingindo profundidades próximas da superfície do solo, com recessão imediata do lençol freático.

\section{CONCLUSÕES}

1. O lençol freático à profundidade média de $1,0 \mathrm{~m}$, durante os cinco ou seis meses de período chuvoso, com recargas temporárias atingindo profundidades próximas da superfície do solo, seguidas de recessão imediata do lençol freático, não foram suficientes para afetar o desenvolvimento e a produtividade da manga, cultivar Keitt.

2. As diferenças na profundidade média do lençol freático entre as posições a $3,5 \mathrm{~m}$, a $10,5 \mathrm{~m}$ e a $17,5 \mathrm{~m}$ do dreno não foram suficientes para causar diferenças significativas no estado da água do solo, nessas posições, durante o período monitorado. 3. O crescimento e produtividade da manga, cultivar Keitt, não foi afetado em condições de porosidade drenada do solo próximo ou superior a $10 \%$. 


\section{REFERÊNCIAS BIBLIOGRÁFICAS}

AGRIANUAL. Anuário da Agricultura Brasileira. São Paulo. 2000. FNP Consultoria.

LARSON, K.D.; SCHAFFER, B.; DAVIES, F.S. Physiological, morphological, and growth responses of mango trees to flooding. Acta Horticulturae, Wageningen, v. 341, p.152-159, 1993.

LARSON, K.D.; SCHAFFER, B.; DAVIES, F.S. Flooding, mineral nutrition and net gas exchange of mango trees. Scientia Horticulturae, Amsterdam, v.52, p. 113. 1992.
MILLAR, S. A. Drenagem de terras agrícolas. São Paulo: McGraw-Hill do Brasil, 1978. 276p.

PIZARRO, F. Drenaje agricola y recuperacion de suelos salinos. Madrid: Editora Agrícola Española, 1978. 521p.

SCHAFFER, B. Stress Physiology. In: LITZ, R. E. (Ed.) The mango: botany, production and uses. Homestead: $\mathrm{Cab}$ Internacional, p. 147-173. 1997. 